\title{
Kolligo: gamificação na educação para experiências de aprendizagem mais engajadoras
}

\author{
Alice Marasca Wiener, Aline de Campos \\ \{alice, aline\}@kolligo.com.br
}

\begin{abstract}
Resumo. O Kolligo oferece uma opção acessível, lúdica e fundamentada em teorias educacionais para incorporação de dispositivos móveis em sala de aula com integração de práticas gamificadas, buscando aumentar a interação entre professores e alunos e estimular o engajamento em experiências de aprendizagem ativa. Além disso, serve como apoio aos docentes na elaboração de práticas diferentes levando em consideração o perfil de cada turma. $O$ aplicativo está disponível para as plataformas iOS e Android, já foi utilizado em contextos de aprendizagem mostrando bons resultados de engajamento $e$ grande potencial para expansão.
\end{abstract}

\section{Contexto e problematização}

O cenário é de crescimento exponencial do acesso a smartphones e seu consequente uso por crianças, jovens e adultos nas mais diversas situações do dia-a-dia. Em contrapartida, no âmbito educacional, os dispositivos móveis não são aproveitados como poderiam, chegando a casos onde são até mesmo proibidos em sala de aula. Esse distanciamento subutiliza esses recursos e reforça uma visão transmissionista de educação, o que vai contra o perfil predominante dos estudantes, uma vez que estão imersos em tecnologia desde cedo e acostumados a diversos estímulos e interações.

Assim, percebe-se uma grande incongruência entre esse perfil e os métodos tradicionais de ensino e aprendizagem, ocasionando pouca interação e engajamento, com grandes problemas de falta de motivação. A motivação intrínseca é originada pelo sujeito, ou seja, vem da vontade própria, de interesses e desafios, através de envolvimento em estímulos de prazer, novidade e entretenimento. Pode surgir da necessidade de satisfação da curiosidade e oportunidades de executar novas habilidades, aprender sobre algo novo. Já a motivação extrínseca é originada por estímulos externos. $\mathrm{O}$ ponto de partida pode ser o desejo de obter uma recompensa externa que pode estar representado em reconhecimento social e/ou bens materiais [Deci e Ryan, 1985; Busarello, 2016].

Há um crescente incentivo ao uso de metodologias ativas de ensino e aprendizagem que pode abrir portas a uma maior interação e engajamento dos alunos enquanto protagonistas do processo. Porém muitas vezes os professores não sabem como aplicar esses métodos e não possuem recursos para os auxiliar. Além disso, mesmo quando querem motivar os alunos em experiências de aprendizagem diferenciadas, acabam ocupando muito tempo elaborando atividades e tentando medir e analisar os dados.

Nesse sentido, percebe-se um cenário favorável no que diz respeito ao acesso aos recursos tecnológicos, ao interesse dos docentes em metodologias ativas e práticas 
VIII Congresso Brasileiro de Informática na Educação (CBIE 2019)

Anais dos Workshops do VIII Congresso Brasileiro de Informática na Educação (WCBIE 2019)

mais interativas e um perfil de alunos que demanda processos mais motivadores que sejam capazes de engaja-los como parte preponderante na experiência de aprendizagem.

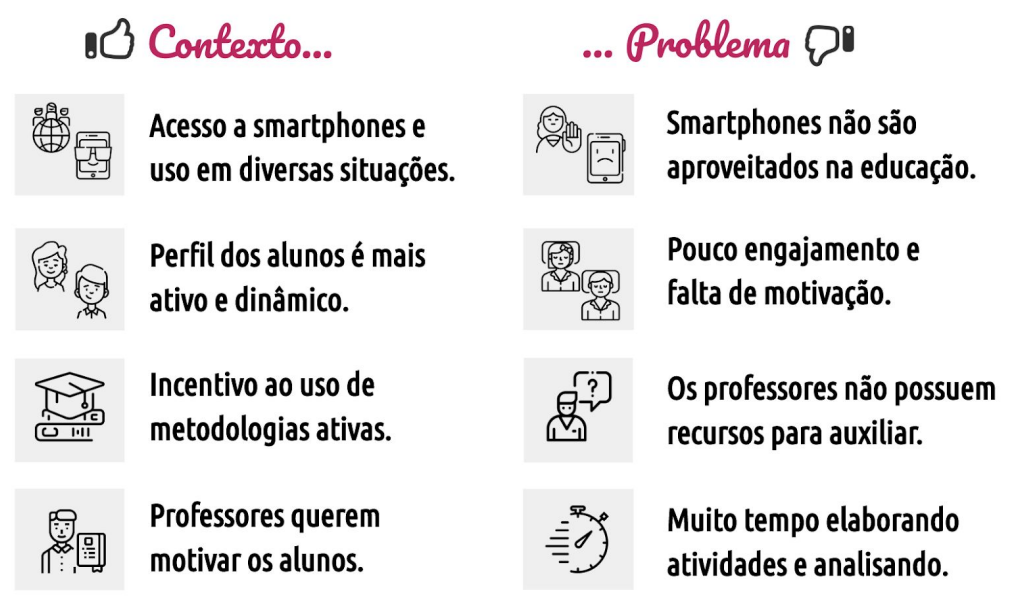

Figura 1. Contextualização e problemas detectados.

A demanda é por práticas fundamentadas em preceitos pedagógicos que possam estimular o engajamento e interação entre professores e alunos. Para tanto, a incorporação de mecanismos de gamificação ganha espaço neste cenário como um processo capaz de usar a mecânica de jogos para além do entretenimento [Dominguez et al., 2013; Zichermann e Cunningham, 2011]. Ou seja, existe a necessidade de recursos acessíveis, com foco numa boa experiência do usuário, que leve em consideração aspectos pedagógicos e que sejam capazes de desenvolver a motivação extrínseca e intrínseca de alunos a partir de processos customizáveis na elaboração de experiências de aprendizagem por parte dos professores.

Tendo em vista o potencial dos processos de gamificação em aplicativos educacionais e a pouca expressão desta integração, foi concebido o Kolligo. Um aplicativo para dispositivos móveis destinado ao uso em sala de aula com suporte a técnicas de gamificação que possam apoiar os processos de aprendizagem. Através de questionários, pontuações, emblemas e conquistas o aplicativo possibilita de forma lúdica e engajadora estimular a interação e integração entre professores e alunos. Além disso, serve como auxílio na tomada de decisão por parte dos docentes, no sentido de oferecer práticas diferenciadas de acordo com o perfil da turma, reconhecer competências e estimular a participação.

\section{Desenvolvimento}

O Kolligo nasceu como um projeto acadêmico, centrado no estudo de perspectivas teóricas e de contextos práticos, tendo como público alvo professores e alunos em experiências de aprendizagem na criação de processos ativos e lúdicos com o uso de gamificação para estimular engajamento e aprendizagem significativa.

Os professores têm a sua disposição a possibilidade de melhorias na interação com alunos, podendo adotar diferentes metodologias e práticas gamificadas customizando as funcionalidades disponíveis de acordo com o perfil de cada turma. $\mathrm{O}$ uso do aplicativo pode otimizar o tempo, além de proporcionar a sistematização do 
progresso dos alunos. Para os alunos, há o oferecimento de um processo mais ativo de experiência de aprendizagem, em um formato mais lúdico e com recursos para estímulos a motivação extrínseca e intrínseca e percepção do seu próprio progresso.

Inicialmente desenvolveu-se um MVP (Minimum Viable Product) para o sistema operacional iOS com vistas a verificar a relevância da ideia junto a um conjunto de docentes e alunos de Ensino Superior. Posteriormente, optou-se por desenvolver uma versão para dispositivos móveis Android usando a tecnologia React Native e buscando ampliar o escopo de potenciais usuários, visto que o mercado de dispositivos móveis para este sistema operacional ainda corresponde a maior parcela.

Novos processos de validação foram realizados junto a professores e alunos e houve ótima aceitação, indicando a possibilidade de expansão do projeto para além do âmbito acadêmico. Para tanto buscou-se maior entendimento em questões relacionadas ao problema, análise de público alvo, análise de concorrência, modelo de negócios, testes da solução e estratégias de marketing e vendas.

Foram realizadas entrevistas em profundidade com docentes de Educação Básica, Técnica e Superior em uma faixa etária entre 29 a 58 anos, com uma média de 10 de experiência em diversas áreas do conhecimento. Percebeu-se que a maior parte dos entrevistados já usou smartphones em atividades e procura recursos para engajamento dos alunos. Além disso, realizou-se um grupo focal com 8 professores para debater recursos utilizados para motivação e engajamento em sala de aula. Gamificação, recursos tecnológicos e smartphones foram citados com recorrência.

Diante dos estudos teóricos que fundamentaram a ideia inicial e das coletas de dados voltados ao aprofundamento do conhecimento de mercado e modelo de negócios, alguns ajustes e melhorias foram realizadas com a decisão de refatorar o aplicativo na tecnologia React Native, uma vez que se trata de um recurso de construção de aplicativos híbridos que possibilita a compilação para ambas as plataformas. Além disso, nessa nova perspectiva, optou-se também por enfatizar as funcionalidades voltadas para gamificação implementando melhorias em sua usabilidade e interface.

Os principais atributos do Kolligo são a gamificação e a customização e nesse sentido posiciona-se em destaque frente aos correlatos (Figura 2). O Kahoot!, conhecido por sua funcionalidade de questionários online, apresenta processos menos elaborados de gamificação e o ClassCraft, que apresenta um processo aprofundado de gamificação, possui uma temática de formato RPG, o que impossibilita uma maior de customização.

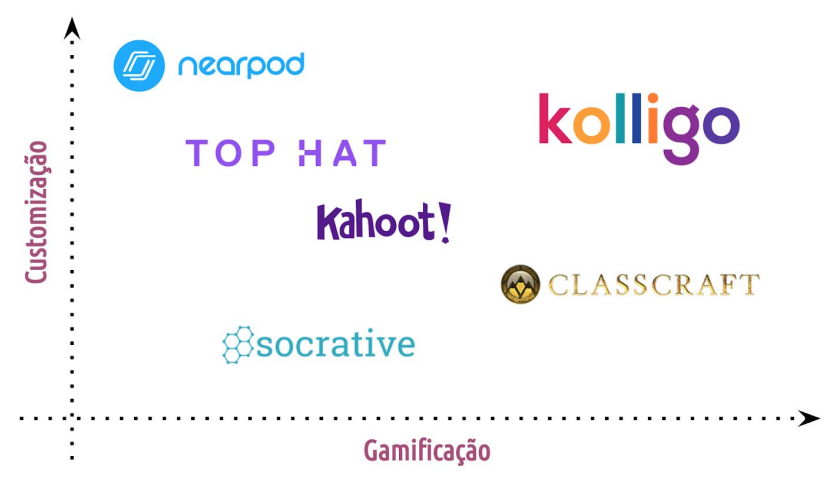

Figura 2. Análise de concorrência frente os atributos principais 
VIII Congresso Brasileiro de Informática na Educação (CBIE 2019)

Anais dos Workshops do VIII Congresso Brasileiro de Informática na Educação (WCBIE 2019)

Assim, além de vantagem em relação aos concorrentes diretos, Kolligo apresenta vantagem relativa aos métodos mais tradicionais de construção de práticas gamificadas, uma vez que muitos professores estruturam atividades de maneira manual com uso de recursos que não são específicos para educação e/ou gamificação.

No que diz respeito a customização, todas as funcionalidades podem ser configuráveis por turma. Isso permite uma maior flexibilidade de adotar ou não determinados de recursos, verificando quais funções se enquadram melhor para cada turma, já que são diferentes e podem reagir de formas diferentes a cada estímulo.

\section{Funcionalidades e aplicações}

O aplicativo Kolligo atualmente encontra-se disponível para download na Google Play na versão para plataforma Android e na App Store na versão para plataforma iOS. $O$ aplicativo tem foco nas interações entre professores e alunos. A criação de usuário é simples e pode ser realizada com autonomia por ambas as partes (Figura 3, primeira tela). O professor pode criar turmas de maneira facilitada (Figura 3, segunda tela) definindo cores, informações gerais e escolher quais funcionalidades devem estar ativadas para essa turma. Com essas opções configuráveis, o professor tem autonomia para definir o que considera mais adequado na construção de sua prática gamificação conforme a necessidades da turma.
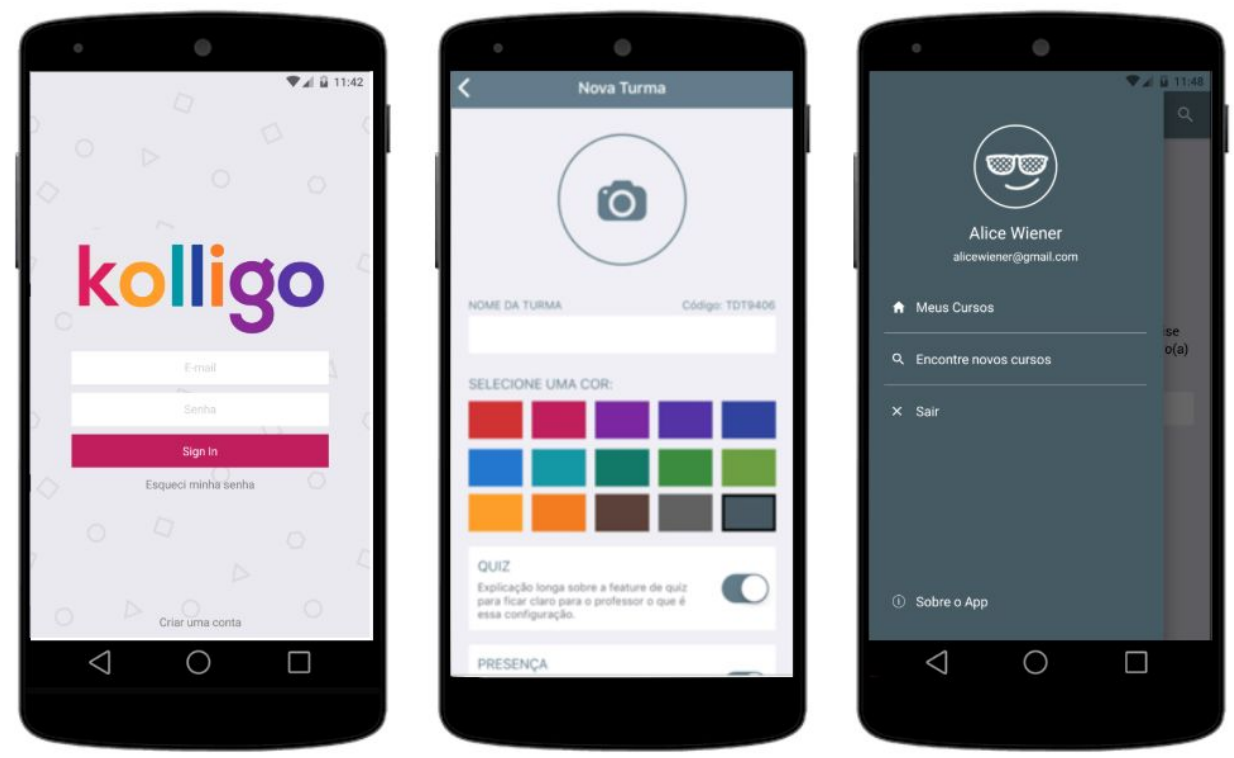

Figura 3. Criação de usuário, criação de turma e menu do aplicativo.

Por sua vez, o aluno poderá acessar o aplicativo e buscar pelas turmas disponíveis. Essa busca pode se dar pelo código, nome da turma ou ainda pelo nome do docente. $\mathrm{O}$ aluno então pode ingressar na turma mediante um código de acesso que será disponibilizado pelo professor. Esse mecanismo foi implementado no sentido de evitar que o acesso indevido em turmas. 

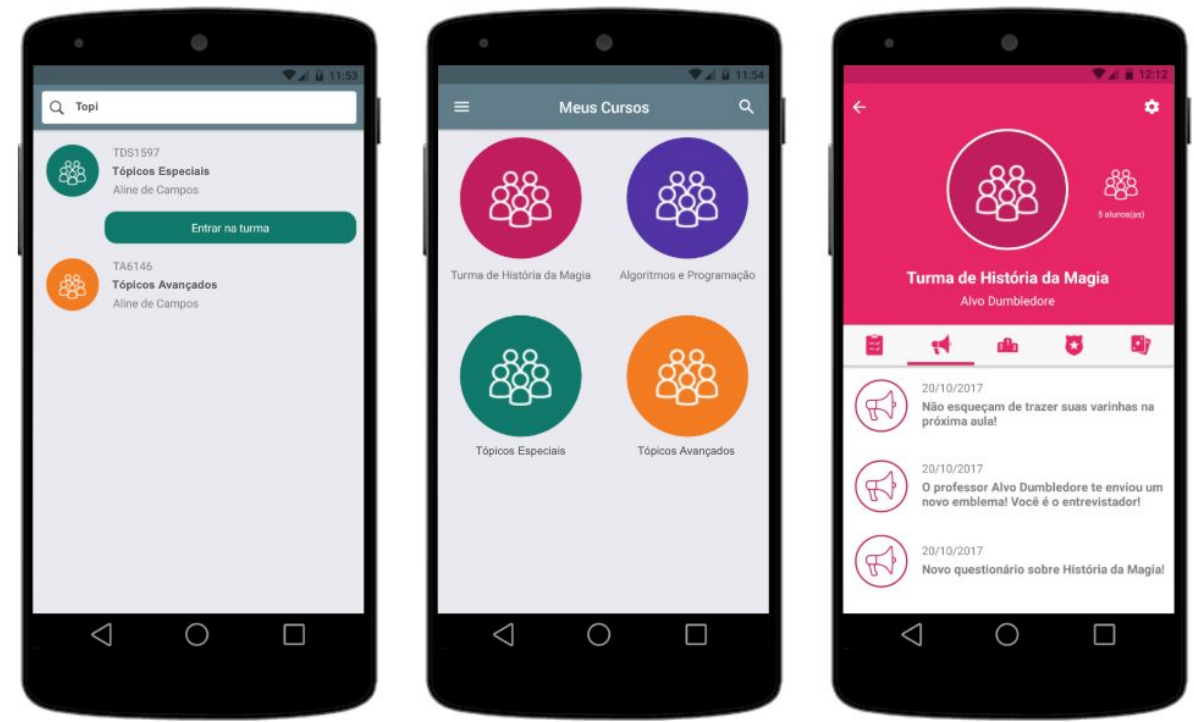

Figura 4. Busca de turmas, listagens das turmas do usuário e detalhe da turma.

Uma das funcionalidades disponíveis é a criação de questionários. Neste recurso, o professor pode criar perguntas com respostas de múltipla escolha, onde pode definir a resposta correta, bem como a quantidade de pontos que o aluno receberá caso acerte. Ainda, pode escolher se a resposta correta deverá ser mostrada ao aluno depois de cada pergunta respondida, ao finalizar ou ainda se não devem ser mostradas.Dessa forma, o professor tem liberdade para conduzir o processo educacional conforme sua necessidade.

Esta função vai ao encontro dos aspectos comportamentais, que levam em consideração a relação estímulo-resposta, onde busca-se instigar os alunos a reflexão de seu entendimento dos conteúdos. Pode ser usada em sala de aula pela turma e o professor pode verificar as respostas com feedback em tempo real, além de poder servir como reforço aos conteúdos trabalhados em aula dentro de experiências de educação híbrida e revisão de conceitos relevantes para evitar a curva de esquecimento.

Sendo assim, os alunos responderão às perguntas (Figura 5, primeira tela) e ao finalizar o questionário uma mensagem e um gif animado serão mostrados (Figura 5, segunda tela). Essa animação é diferente para cada pontuação alcançada. A ideia é oferecer um suporte lúdico de incentivo, mesmo que o aluno não tenha conseguido uma boa pontuação. $\mathrm{Na}$ medida que a turma responde ao questionário, o professor pode visualizar o gráfico de respostas com a porcentagem de alunos que escolheram as alternativas (Figura 5, terceira tela). Além disso, pode visualizar a lista de alunos que responderam e quais as alternativas eles escolheram e, dessa forma, pode avaliar rapidamente o andamento da aula e visualizar quais assuntos necessitam ser revisados.

Uma das mecânicas mais relevantes de gamificação é o ranking (Figura 5, quarta tela). No Kolligo, ele é estabelecido a partir do questionário e de pontos que podem ser oferecidos pelo professor ao aluno de acordo com ações realizadas dentro e fora do aplicativo. Dada a natureza customizável do aplicativo, o professor pode 
VIII Congresso Brasileiro de Informática na Educação (CBIE 2019)

Anais dos Workshops do VIII Congresso Brasileiro de Informática na Educação (WCBIE 2019)

escolher ativar ou não esta funcionalidade tendo em vista o objetivo pedagógico da experiência gamificada que pretende promover.
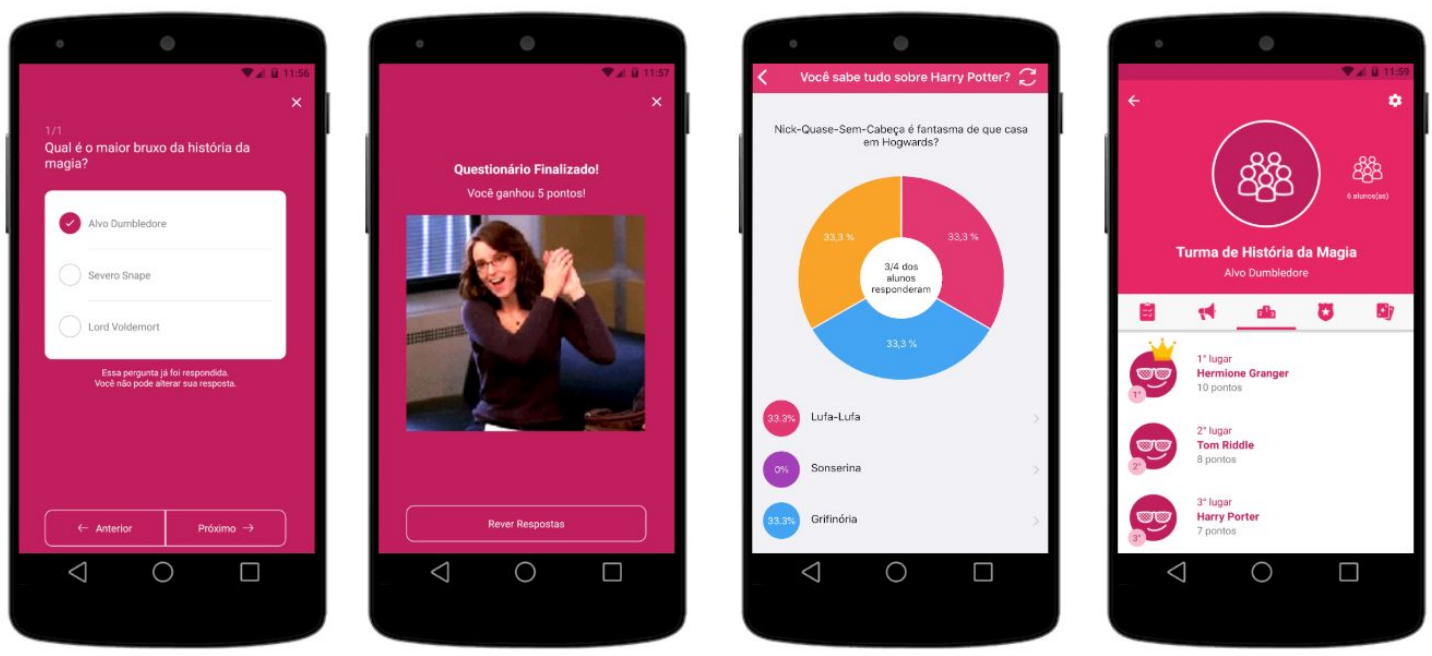

Figura 5. Questionário sendo respondido pelo aluno, tela final do quiz com pontuação e gif, tela de resultados visualizado pelo professor e ranking.

Outros dois recursos de gamificação são os emblemas (badges) e cartas. Os emblemas são conquistas realizadas dentro do processo de gamificação, ou seja, quando uma ação é realizada dentro ou fora do aplicativo atendendo a mecânica definida (Figura 6, primeira tela). Em geral, este tipo de recurso de gamificação é usado para que o participante sinta-se obtendo status social pelo esforço realizado. Por exemplo, se ele acertar todas as perguntas de um questionário por duas vezes consecutivas, ele pode ganhar um badge como uma estrela de ouro. Essa funcionalidade é focada na autorrealização, na satisfação e no crescimento pessoal do aluno, onde os sentimentos e ações são integrados. Além disso, esse recurso pode servir para oferecer feedbacks construtivos e bem humorados. Por exemplo, na Figura 6 (segunda tela), mostra o badge do Entrevistador, que pode ser usado para dar um feedback bem humorado para um aluno que está conversando muito em sala de aula.

Já as cartas são expressões de valorização das ações do aluno pelo professor, uma forma de reconhecimento (Figura 6, terceira tela). Por exemplo, o professor libera uma carta para quem realizar uma atividade extraclasse. Na carta, o aluno conquista a possibilidade de aumentar em um ponto a nota de um trabalho ou prova e pode escolher quando utilizar. Essa sensação de conquista está ligada também ao sentimento de propósito de se envolver em uma atividade, bem como estímulo a autonomia (Figura 6, quarta tela). Além disso, as cartas trabalham a autonomia do aluno, já que ele pode decidir quando a carta será utilizada. 
VIII Congresso Brasileiro de Informática na Educação (CBIE 2019)

Anais dos Workshops do VIII Congresso Brasileiro de Informática na Educação (WCBIE 2019)
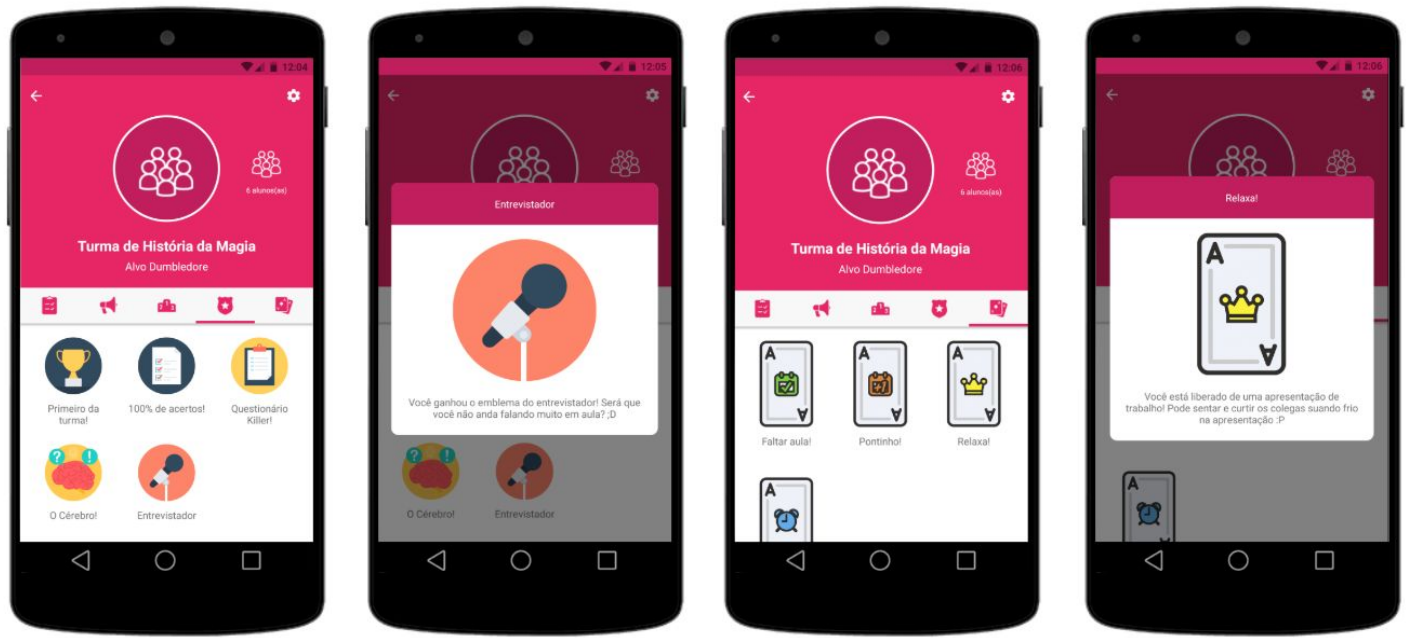

Figura 6. Lista de badges conquistadas por um aluno, detalhe do badge do Entrevistador, lista de cartas de um aluno e detalhe da carta.

\section{Considerações finais}

O aplicativo Kolligo ${ }^{1}$ conquistou o terceiro lugar na categoria Protótipo do Concurso AppsEdu no Congresso Brasileiro de Informática na Educação em 2018. Em Janeiro de 2019, foi selecionado no Programa StartupRS do Sebrae, onde durante cinco meses com workshops e mentorias, o produto foi reformulado e trabalhou-se no modelo de negócios, buscando analisar o mercado de educação e tecnologia, os concorrentes, as formas de monetização e abordagens de vendas para sustentabilidade financeira. Ao final do programa em Julho de 2019, Kolligo conquistou o segundo lugar entre as 19 participantes do programa.

Abriu-se então foco para ampliação do projeto, buscando implementar outras funcionalidades relativas a gamificação, bem como expandir a atuação de B2C (Business-to-Consumer) focada a professores e facilitadores de práticas educacionais, para atender também uma abordagem B2B (Business-to-Business) com atenção às instituições de ensino e centros de capacitação.

Está em fase de desenvolvimento uma interface web para gestão de dados por parte dos professores uma vez que identificou-se que pode facilitar o uso no momento do criação de questionário e gerenciamento de turmas por parte do professor. Para o ano de 2020, pretende-se que esta estrutura web expanda-se para uma interface de Learning Analytics com vistas ao desenvolvimento de processos de personalização de aprendizagem compondo juntamente com o aplicativo uma plataforma educacional que atenda instituições, professores e alunos em diversos níveis.

\section{Referências}

Busarello, R. I. Gamification: princípios e estratégias. São Paulo: Pimenta Cultural, 2016.

\footnotetext{
${ }^{1}$ Anteriormente o aplicativo chamava-se Colligo. A partir de Janeiro de 2019 passou a ser chamado de Kolligo como uma estratégia de posicionamento no mercado e marketing.
} 
VIII Congresso Brasileiro de Informática na Educação (CBIE 2019)

Anais dos Workshops do VIII Congresso Brasileiro de Informática na Educação (WCBIE 2019)

Deci, E. L., Ryan, R. M. Intrinsic motivation and self-determination in human behavior. New York: Plennum Press, 1985.

Domínguez, A., Navarrete, J. S., Marcos, L., Sanz, L. F., Pagés, C. and Herráiz, J. J. M. (2013) "Gamifying learning experiences: Practical implications and outcomes". In Journal Computers \& Education, p. 380-392.

Zichermann, G. and Cunningham, C. (2011) "Gamification by Design: Implementing Game Mechanics in Web and Mobile Apps". O’Reilly. 